\title{
Nursing Student Engagement: Taking a Closer Look $^{*}$
}

\author{
Kathleen Hudson, Rebecca Carrasco \\ Longview University Center, University of Texas at Tyler, Tyler, TX, USA \\ Email: Khudson@uttyler.edu
}

How to cite this paper: Hudson, K. and Carrasco, R. (2017) Nursing Student Engagement: Taking a Closer Look. Open Journal of Nursing, 7, 193-201. https://doi.org/10.4236/ojn.2017.72017

Received: December 1, 2016

Accepted: February 13, 2017

Published: February 16, 2017

Copyright $\odot 2017$ by authors and Scientific Research Publishing Inc. This work is licensed under the Creative Commons Attribution International License (CC BY 4.0).

http://creativecommons.org/licenses/by/4.0/

\begin{abstract}
Nursing student engagement is a critical and enhancing means of ensuring students stay within their education, and subsequently within the nursing profession. Engaged students with having higher ethical standards and behaviors, are certainly "caring" with their care delivery, and are dependable and competent with their teamwork. These are rewarding aspects of nursing practice. This research evaluates student nurses' perceptions and their sense of engagement in relation to nursing and their educational experiences.
\end{abstract}

\section{Keywords}

Engagement, Student Nurse Engagement, Nursing Education, Nursing Practice

\section{Background}

Student engagement has many definitions, and includes time, effort, resources, participation, activities, emotions, and feelings within the context of embracing student learning [1]. Student engagement is a measure for ongoing assessment of the quality of the nursing program and the success of graduation students.

Nursing student engagement is critical for success within nursing programs and with the goal of remaining within the profession with longevity once the students graduate. There are three levels to focus on in relation to student engagement: engagement between the student and teacher, the student connection with their learning, and the student linking with their learning environment [2]. Engagement also involves therapeutic engagement which consists of empathy, active listening and collaboration [3]. Nurse educators demonstrate integrity, authenticity, caring, and support for nursing students in efforts to assist their

${ }^{\star}$ Special appreciation to: Ashlee Health, secretarial support, University of Texas Tyler; Zhaomin He, Assistant Professor, statistical support, University of Texas Tyler. 
learning of appropriate skills and knowledge so they can constructively and "caringly" replicate these practices when they provide care for patients.

Nursing is currently undergoing rapid changes of environments, procedures, and general workforce life. Hospitals are undergoing renovations to establish user-friendly environments. Additionally, care is transitioning to more community-home based settings, away from hospital settings. The ability to use technology to transmit information is critical for these changes. Learning itself is undergoing changes. No longer should didactic lecturing be the main presentation of course materials. Today's teaching styles involve problem solving activities, team (group) learning and tasking, video presentations and on-line learning, case studies, simulation laboratories, active community projects, and much more. The ability to communicate in different ways to and for students assists in their engagement and content retention levels. Although simulation has become popular and necessary within campuses where clinical sites are few, the actual clinical setting has a stronger effect on enhancing clinical performance than a simulation experience does ([4], p. 156).

Active learning is a component of engaged learning. Active learning can be fostered into discussions. This stimulates students into supporting their points, and at the end, creates a collaborating learning environment. These types of discussions will provide teamwork and group communication skill development which is highly needed within clinical settings. The current trends are urgently transitioning into all on-line learning platforms. Can on-line learning of core interactive nursing skills be as effective as active classroom interactive learning? Are new nurses entering the workforce without adequate and necessary interactive skills required for quality interactions when providing nursing care? Are online taught nurses interacting differently in the clinical settings? These are important questions.

The interconnectedness between courses is still in its infancy. As more education is occurring on-line, the speed of delivery of each course and course content can be catered to the individual learner's capacity. Additionally, experiential learning from job experience can remove some of the redundant learning for some students. These students can test-out of specific courses they are already skilled with and competent in by taking examinations to demonstrate knowledge already gained.

Students need to develop engagement with their studies which will carry over into their clinical practice. Engagement with the clinical environment has its own challenges and rewards. The preceptors perform vital roles in demonstrating quality care and positive interactions with patients. With support provided to students when they are learning and reflecting on the care they are giving, they develop critical skills core for successful nursing, and positive affects toward encouraging their patients toward better wellness. This is also important on an individual level. Stress management, relaxation techniques, and reflection are all strategies to assist to effectively decrease stressors and increase the sense of engagement [5]. These should be basic parts within a nursing program. 
Nursing educational settings are developing their infrastructures to support and emphasize EBP and evidence-base decision-making (EBDM). These focuses are key engagement stimulants toward caring for their care delivery and providing quality within the nursing student-to-patient interactions. Engaged students (future nursing staff) are fundamental to providing appropriate and high quality of care. However, work is still underway with trying to find the best means to stay updated with current releases of best evidence. Getting these advances efficiently into clinical practice remains a challenge. Hospitals with commitment to developing their nurses have developed practice councils, evidence-based practice (EBP) councils, and other forms for updating and delivering best practice to the bedside. Student nurses need exposure to these implementation formats to become more aware of and influential with patients and families as changes occur and advances are put into place within the clinical settings.

The traditional values of nursing remain core to nursing student education. According a study by Tuckett [6], student nurses, "love nursing because they find the work in and of itself dynamic and having for them an instrumental value... (they) love nursing because it is defined by who they care for and also who they care about. That is, the people: client, patient, family, workmate (p. 260)". Maintaining these caring attitudes during their nursing careers provides a foundation for 'quality caring' care delivery. One of the challenges of nursing education is developing resilience so students can maintain their senses of caring and engagement [7]. Resilience is linked to engagement.

\section{Methods}

This study further expands previous research investigating student engagement. [8], by now including an additional (same university) campus. This study was approved by the university's Institutional Review Board and the nursing department's leadership. The samples are from second and fourth level nursing students at two undergraduate nursing sites of an eastern Texas University. These campuses are labeled Site A and Site B. All students registered and participating in the class were eligible to participate in the survey. There were no exclusions for this survey. Students carried out their usual nursing education as per requirements, and subsequently filled out student engagement questionnaires, in a post-test format, to identify their levels of engagement with their nursing courses to date. The Student Engagement Questionnaire [9] [10] [11] includes 35 questions, with responses marked on a one to five Likert scale. The questionnaire concludes with 2 short open-ended qualitative questions about: 1) "What are the best aspects of the program?", and 2) "What aspects are in most need of improvement?". There were no anticipated negative effects related to filling out the survey form. Analyses including descriptive, statistical factorial ANOVA, and qualitative review were utilized when comparing results.

\section{Findings}

This study's findings (see Table 1) include the following responses to the fol- 
Table 1. Survey Answers for Level 2 and Level 4 for Each Campus.

Questions

1. I have developed my ability to make judgments about alternative perspectives

2. I have become more willing to consider different points of view

3. I have been encouraged to use my own initiative

4. I have been challenged to come up with new ideas

5. I feel I can take responsibility for my own learning

6. I have become more confident of my ability to pursue further learning

7. During my time at university I have learned how to be more adaptable

8. I have become more willing to change my views and accept new ideas

9. I have improved my ability to use knowledge to solve problems in my field of study

10. I am able to bring information and different ideas together to solve problems

11. I have developed my ability to communicate effectively with others

12. In my time at university I have improved my ability to convey ideas

13. I have learned to become an effective team or group member

14. I feel confident in dealing with a wide range of people

15. I feel confident in using computer applications when necessary

16. I have learned more about using computers for presenting information

17. Our teaching staff use a variety of teaching methods

18. Students are given the chance to participate in classes

19. The teaching staff try hard to help us understand the course material

20. The course design helps students understand the course content

21. When I have difficulty learning materials, I find the explanations from teaching staff useful

22. The assessment tested our understanding of key concepts in this program

23. The program uses a variety of assessment methods

24. To do well in this program you need to have good analytical skills

25. The assessment tested our understanding of key concepts in this program

26. The communication between teaching staff and students is good

27. I find teaching staff helpful when I ask questions

28. I manage to complete the requirements of the program without feeling unduly stressed

29. The amount of work we are expected to do is quite reasonable

30. I feel a strong sense of belonging to my class group

31. I frequently work together with others in my classes

32. I have frequently discussed ideas from courses with other students out of class

33. I have found that discussing course material with other students out of class has helped me reach a better understanding of the material

34. I can see how courses fit together to make a coherent program of study for my major

35. The program for my major was well integrated

\begin{tabular}{|c|c|c|c|}
\hline $\begin{array}{l}\text { Site A } \\
\text { level } 2\end{array}$ & $\begin{array}{c}\text { Site A } \\
\text { Level } 4\end{array}$ & $\begin{array}{c}\text { Site B } \\
\text { Level } 2\end{array}$ & $\begin{array}{c}\text { Site B } \\
\text { Level } 4\end{array}$ \\
\hline 4.6 & 4.2 & 4.4 & 4.5 \\
\hline 4.8 & 4.4 & 4.6 & 4.7 \\
\hline 4.6 & 4.6 & 4.5 & 4.6 \\
\hline 4.8 & 4.2 & 4.4 & 4.5 \\
\hline 4.9 & 4.8 & 4.6 & 4.7 \\
\hline 4.7 & 4.2 & 4.5 & 4.6 \\
\hline 4.5 & 4.2 & 4.7 & 4.6 \\
\hline 4.6 & 4.2 & 4.5 & 4.4 \\
\hline 4.7 & 4.4 & 4.6 & 4.7 \\
\hline 4.4 & 4.4 & 4.6 & 4.5 \\
\hline 4.4 & 4.4 & 4.5 & 4.5 \\
\hline 4.3 & 4.2 & 4.4 & 4.4 \\
\hline 4.5 & 4.4 & 4.4 & 4.6 \\
\hline 4.7 & 4.4 & 4.5 & 4.5 \\
\hline 4.4 & 4.5 & 4.5 & 4.4 \\
\hline 4.3 & 3.9 & 4.2 & 4.2 \\
\hline 4.7 & 3.8 & 4.4 & 4.3 \\
\hline 4.8 & 4.5 & 4.5 & 4.7 \\
\hline 4.8 & 4.3 & 4.6 & 4.5 \\
\hline 4.4 & 4 & 4.5 & 4.4 \\
\hline 4.5 & 4 & 4.3 & 4.2 \\
\hline 4.6 & 3.8 & 4.3 & 4.4 \\
\hline 4.7 & 3.6 & 4.1 & 4.3 \\
\hline 4.6 & 4.2 & 4.4 & 4.5 \\
\hline 4.5 & 4.4 & 4.4 & 4.4 \\
\hline 4.7 & 4.3 & 4.5 & 4.4 \\
\hline 4.8 & 4.4 & 4.5 & 4.4 \\
\hline 3.4 & 3 & 3 & 2.7 \\
\hline 3.9 & 3.6 & 3.4 & 3.4 \\
\hline 4.4 & 3.8 & 4.1 & 4.3 \\
\hline 4.0 & 3.9 & 4.1 & 4.6 \\
\hline 4.3 & 4 & 4.2 & 4.3 \\
\hline 4.4 & 4.4 & 4.4 & 4.5 \\
\hline 4.7 & 4.4 & 4.5 & 4.5 \\
\hline 4.7 & 4.5 & 4.6 & 4.4 \\
\hline
\end{tabular}


lowing student engagement questions. Data for campus A: levels 2 and 4, and campus B: levels 2 and 4 are presented. The potential responses were designated as: 1: strongly disagree, 2: disagree, 3: definite answer not possible, 4: agree, and, 5: strongly agree.

\subsection{Quantitative Findings}

Overall, the means showed, in general, the students are highly engaged on both campuses. The main effect for site was non-significant. There were significant interaction effects due to the difference between the group levels on the smaller campus.

Intellectual: the interaction effect was significant, with a small effect size ( $\mathrm{p}=$ 0.037), with the difference lower for level 4 than level 2 on smaller campus.

Working together. students' engagement in terms of working together remained the same across campuses and levels.

Teaching: significant main effect for level $(\mathrm{p}=0.005)$ with the difference lower for level 4 than level 2 on smaller campus; no significant difference on larger campus.

Teacher-student relationship: significant difference on smaller campus $(\mathrm{p}=$ 0.008) with the difference lower for level 4 than level 2; no significant difference on larger campus.

The students' report demonstrates a general high level of engagement and satisfaction with the campuses' teaching/learning environment. The main areas for follow-up are the responses to questions 28 and 29 which address students' perception of their stress levels. And, although small sample sizes, the general overall decrease from level 2 to level 4 on the smaller campus.

\subsection{Qualitative Findings}

The nursing students reported the following in reference to their feelings and perceptions of the nursing program:

\section{What are the best aspects of the program?}

Environment: The whole environment is very positive; It is nice having a smaller campus- The small class load made me feel more connected; All the staff help out; Class size; The university provides great resources to get through the program; campus size and faculty involvement; more awareness and decision making ability on the campus;

Course: the way the program is broken up each semester-the courses are fitting for each level; it is organized;

Classes. The classes of the group, accessibility to instructors \& the clinical exposure; Very flexible, great staff \& great communication; Small class sizes. Material is hard enough to weed out people unfit for nursing; small, close nit;

Teachers. always available! There are some really good teachers; Professors are very positive and strive to do their very best to teach us everything we need to know; Teacher/student communication was very helpful!; relationships between teachers \& students; The instructors are very helpful and willing to teach if you 
want to work hard and learn; The best aspect of my program is the teachers willingness to help their students. They meet up with students anytime they are in need of extra help; The best aspects of my program is that I am able to consult with my teacher if I am having problems \& able to ask questions $\&$ be given rationales; staff-student relationship allows students confidence to ask questions; love how enthusiastic the teachers are about providing learning experiences;

Clinical: The clinical experience; the instructors are very good with communication \& instructions.

\section{What aspects are in most need of improvement?}

A better study room; I don't know if it feasible but I think the med-surg content needs to be more spread out; None; organizational problems-not confirming with clinical sites before having us show up; exam times-I personally prefer earlier but most do not!; overall the program design is excellent. Great set of instructors!; use of technology; maybe not cram everything into April!; more time for self-care; some of the lecturing; collaboration with other campuses on tests. The instructors should take the test as well to ensure no errors; lecture, we can watch lectures on-line, class time should be used to help us learn, or make them online classes; unsure; the time required for each clinical needs a little improving. I feel that some clinical experiences are longer than need be; communication; need more on-line classes; space; study support for level 1 and 2; close gap between test taking and course content- need improvement in test taking as it relates to course material

\section{Discussion}

The data clearly demonstrate the nursing education the students are currently receiving is engaging, which is likely to be carried over into their new work environments. The overall goal of having well prepared and engaged students entering the workforce was achieved. The educational style and educators' teaching methods appear to provide the foundations for students to feel engaged with their learning and future perspectives.

The one area which is highlighted as a 3 or 2.7 is the experience of 'stress' the students feel overall during their education (questions 28 and 29). There is a stress management program currently in place in which students participate. This formally occurs three times during the semester, and includes: stress management, time management, professional boundaries, and test anxiety. Students can participate in individual sessions for specific problems they are experiencing. Students are also encouraged to seek counselling if their individual needs warranted it during the semester Student strategies for stress management are an area for further investigation and intervention planning. The areas to focus on are "organizing, prioritizing, communicating, and demonstrating leadership" as these areas are important for all levels of stakeholders within the organization [12]. When students are better prepared to deal with the diverse and numerous stressors, they will be more successful with their studies, the transition into practice, and the actual care environment. According to Harrill, Lawton and Fa- 
bianke [13], the whole student needs to be supported. This requires efforts be made to address social, financial, emotional, or other barriers which are inhibiting their quality learning. This area has a focus within the campus at present. However, this does not currently appear to be effective as the scores were low on these markers.

Study groups, when done well (students clarify various areas of weakness for each other and correcting mistakes that occur), will assist to create stronger feelings of engagement between students. This is both emotional and cognitive sharing and learning that are occurring. These interactions are also building interpersonal skills and behaviors which are extremely important in 'service' provision. Nursing has an excellent reputation for quality service, and these skills are important to maintain.

Issues surrounding all on-line verses hybrid (blended) verses full face-to-face classroom education styles currently exist within the curriculum. Each teaching style has its own strengths and weaknesses. Most classes today are 'flipped classes' where students must prepare before the class on the topic which is outlined on their syllabus. This is often monitored by scheduled quizzes or exercises which demonstrates their prior preparation. Some courses may have participation grades. It is important to monitor the level of participation in the given activities, and provide feedback to students as to areas of improvement. There is also a strong commitment to developing effective interpersonal skills with students, especially when they are in the clinical environment. In fact, their level of interaction is evaluated both in the classroom and when they are out on clinical practice assignments. Feedback is provided individually for each student with the communication goals clearly defined. This demonstrates the organizational commitment to a culture of 'evidence and inquiry' as discussed by Harrill, Lawton, and Fabianke [13]. They state:

“...to continuously examine the students' experiences, progression, and outcomes, and these analyses inform the creation, implementation, and evaluation of their strategy to enhance the student experience and increase outcomes (p. 11)."

The students' sense of engagement is critical to their persistence and success of their informal and formal education.

The next step is to ensure the work environment maintains and exceeds the current engagement levels, if possible. The beginning phases of "real" nursing practice are sometimes met with unrealistic expectations. New nurses need to be supported and develop through these phases which progress during their first year in practice: the "honeymoon phase" and the "reality shock phase" will be unavoidable experiences as they mold into competent care providers. How these phases are managed by the practice educators, the clinical leaders and fellow staff will be important. This situation requires good teamwork and coordination for the new nurses to acclimate well.

Issue with certain students that do not find a study group due to a personality 
issue, this could be a barrier for student engagement also a risk within the nursing profession as communication is key for patient and staff safety. Engagement is indirectly assessed by the educators throughout the semester. These students could be identified and provided with additional support toward developing stronger Inter professional skills for their group work in addition to skills for improving interactions within their clinical practice environments.

Rush, Adamack, Gordon, Janke, and Ghement [12] discuss the importance of "solid orientation and transition programs as assisting the transition into workplace integration". They identified the importance of the length of formal transition support, with students acclimating better with longer integration support periods. We recommend this transition period be integrated into the unit's support plan with an ongoing both "team" and "interpersonal" support mechanisms well developed to support all levels of staff. This effort is to enhance and maintain engagement within their nursing practice.

An anecdotal area of interest is the volunteerism that is carried during the nursing educational program. Could this education format develop more volunteerism within the students which will carry-over into their life after graduation? Volunteerism is gratifying for the volunteers, and certainly, very beneficial for the persons receiving the efforts provided.

The limitations of this research: 1) include the small site's limitation in number of students; 2) did not include the third campus, which will be addressed with future research efforts, however-it also is a small campus with limited number of nursing students; and 3) include survey was offered during class time, and some students did not attend the specific date of the survey.

\section{Conclusion and Recommendations}

Overall, this study supports efforts to monitor and assess student perceptions of their sense of nursing engagement. These results can be used to assess responses to curricular changes and format adjustments which impact their learning styles and/or environments. Nursing is a complex area to learn, understand, and integrate into a high quality profession. Efforts to enhance or increase student/ nursing engagement will inherently affect their responses to each other and the care style they exhibit during practice. The following recommendations are presented:

- Provide diverse curricular educational formats to stimulate all types of learners and maintain commitment and interests of all students;

- Group learning (including individualized feedback) toward increasing effective "teamwork" which is a job requirement for quality nursing care today;

- Ensure all educators are engaged and committed to student learning to assist in creating both healthy and beneficial well-rounded student outcomes;

- Allow student choices during the classes, which will provide a wonderful learning opportunity and enhance the sense of "belonging to learning" which is fundamental to develop lifelong learning skills and commitment (and ongoing high quality nursing staff with high quality performance); 
- Encourage roles which develop well-roundedness, reflection, preparation, commitment, caring, sharing and openness within the learning environment as these will become part of the students' sense of engagement and important components of their skill sets once they graduate.

\section{References}

[1] Hampton, D. and Pearce, P.F. (2016) Student Engagement in Online Learning Nursing Courses. Nurse Educator, 41, 294-298. https://doi.org/10.1097/NNE.0000000000000275

[2] Bowcock, R. and Peters, K. (2016) Discussion Paper: Conceptual Comparison of Student and Therapeutic Engagement. Nurse Education in Practice, 17, 188-191. https://doi.org/10.1016/j.nepr.2015.10.010

[3] Bright, F.A.S., Kayes, N.M., Worrall, L. and McPherson, K.M. (2014) A Conceptual Review of Engagement in Healthcare and Rehabilitation. Journal of Disability Rehabilitation, 37, 643-654.

[4] Pai, H.-C. (2016) An Integrated Model for the Effects of Self-Reflection and Clinical Experience Learning on Clinical Nursing Performance in Nursing Students: A Longitudinal Study. Nurse Educator Today, 45, 156-162. https://doi.org/10.1016/j.nedt.2016.07.011

[5] Gregg, S.R. and Twibell, K.R. (2016) Try-It-On. Journal of Holistic Nursing, 34, 300-308. https://doi.org/10.1177/0898010115611788

[6] Tuckett, A. (2015) Speaking with One Voice: A Study of the Values of New Nursing Graduates and the Implications for Educators. Nurse Education in Practice, 15, 258-264. https://doi.org/10.1016/j.nepr.2015.02.004

[7] Reyes, A.T., Andrusyszyn, M.A., Iwasiw, C., Forchuk, C. and Babenko-Mould, Y. (2015) Nursing Students' Understanding and Enactment of Resilience: A Grounded Theory Study. Journal of Advanced Nursing, 71, 2622-2633. https://doi.org/10.1111/jan.12730

[8] Hudson, K. and Carrasco, R. (2015) Researching Nursing Students' Engagement: Successful Findings for Nursing. International Journal of Nursing \& Clinical Practices, 2, 150. https://doi.org/10.15344/2394-4978/2015/150

[9] Kemplar, D. (2005) Best Practice in Outcomes-Based Teaching and Learning at the Chinese University of Hong Kong. Centre for Learning Enhancement and Research, Hong Kong.

[10] D’Souza, M.S., Venkatesaperumal, R., Radhakrishnan, J. and Balachandran, S. (2013) Engagement in Clinical Learning Environment among Nursing Students: Role of Nurse Educators. Open Journal of Nursing, 3, 25-32. https://doi.org/10.4236/ojn.2013.31004

[11] Hudson, K. and Carrasco, R. (2015) Nursing Student Engagement: Student, Classroom, and Clinical Engagement. International Journal of Nursing, 4, 44-52.

[12] Rush, K.L., Adamack, M., Gordon, J., Janke, R. and Ghement, I.R. (2016) Orientation and Transition Programme Component Predictors of New Graduate Workplace Integration. Journal of Nursing Management, 23, 143-155. https://doi.org/10.1111/jonm.12106

[13] Harrill, M., Lawton, J.A. and Fabianke, J.-C. (2015) Faculty and Staff Engagement: A Corecomponent of Student Success. Peer Review, 17, 11-14. 
Submit or recommend next manuscript to SCIRP and we will provide best service for you:

Accepting pre-submission inquiries through Email, Facebook, LinkedIn, Twitter, etc. A wide selection of journals (inclusive of 9 subjects, more than 200 journals)

Providing 24-hour high-quality service

User-friendly online submission system

Fair and swift peer-review system

Efficient typesetting and proofreading procedure

Display of the result of downloads and visits, as well as the number of cited articles Maximum dissemination of your research work

Submit your manuscript at: http://papersubmission.scirp.org/

Or contact ojn@scirp.org 